\title{
Strength on cut edge and ground edge glass beams with the failure analysis method
}

\author{
Stefano Agnetti \\ Department of Engineering, University of Perugia, Italy \\ stefano.agnetti@gmail.com
}

\begin{abstract}
The aim of this work is the study of the effect of the finishing of the edge of glass when it has a structural function.

Experimental investigations carried out for glass specimens are presented. Various series of annealed glass beam were tested, with cut edge and with ground edge. The glass specimens are tested in four-point bending performing flaw detection on the tested specimens after failure, in order to determine glass strength. As a result, bending strength values are obtained for each specimen.

Determining some physical parameter as the depth of the flaw and the mirror radius of the fracture, after the failure of a glass element, it could be possible to calculate the failure strength of that.

The experimental results were analyzed with the LEFM theory and the glass strength was analyzed with a statistical study using two-parameter Weibull distribution fitting quite well the failure stress data.

The results obtained constitute a validation of the theoretical models and show the influence of the edge processing on the failure strength of the glass. Furthermore, series with different sizes were tested in order to evaluate the size effect.
\end{abstract}

SOMMARIO. Il lavoro presentato ha lo scopo di valutare la resistenza di elementi in vetro. Il vetro, materiale elasto-fragile per la sua struttura chimica amorfa, raggiunge la rottura in modo improvviso per valori di resistenza piuttosto dispersi a causa della presenza dei difetti sui bordi del vetro.

Sono stati eseguiti test a flessione su quattro punti su elementi in vetro float con differenti finiture superficiali, per valutare l'influenza della lavorazione dei bordi sulla resistenza. Sono state testate alcune serie di elementi con bordi tagliati e altre con bordi molati. Solitamente la rottura di un elemento in vetro avviene a partire del difetto di maggiore grandezza, nella zona maggiormente sollecitata. Grazie alla lavorazione dei bordi si riesce a ridurre l'ampiezza dei difetti, che, sebbene di minore grandezza, sono ugualmente presenti nel vetro.

La resistenza del vetro è stata determinata attraverso la teoria della meccanica della frattura lineare e mediante l'analisi post-rottura della superficie da cui si genere la frattura. L'analisi sperimentale ha permesso di valutare l'efficacia della finitura dei bordi in termini d'incremento della resistenza del vetro e la validazione dei modelli per la determinazione della resistenza.

KEYwORDS. Edge strength; Fracture mechanic; Glass flaw; Grinding; Size effect.

\section{INTRODUCTION}

$\mathrm{F}$ or hundreds of years, glass has been used as windows in buildings, while research on structural applications of glass has only just begun. In recent years, the knowledge on glass properties has expanded, bringing to light new ways of using glass, such as full transparent construction. Due to transparent nature of glass, it is used in multiple ways by 
engineers and architects and today the research is further advancing at the field of studying glass properties both in structural aspects and in relation to building technology, energy and light.

But glass is a challenging material due to its brittle feature. In order to use glass safely in structural applications, knowledge about its strength is required. The presence of the flaw in glass causes the failure [1]. The fracture mechanics shows how the failure depends on the depth of the flaw, on the number of them and also on the stress corrosion (called static fatigue in literature) [2]. The stress corrosion causes subcritical crack growth in glass. The crack propagation phenomenon occurs in glass when it is exposed to tensile stress and humidity. The particular flaw that produces the fracture is generally called the critical flaw.

The processing of the edge of structural glass is studied; the edge has an important role to determine the failure. Indeed the finishing of the edge could remove in part the flaws or in other case it could produce other micro-cracks, without nobenefit for the strength of the glass [3]. The most important type of edge processings object of study [4] are grinding and polishing

The strength of the glass can be evaluated through the fracture surface analysis: determining some physical parameter as the depth of the flaw and the mirror radius of the fracture after the failure of a glass element, it could be possible to calculate the failure strength of that [5]. For this evaluation, it was tested a group of glass element, in bending. It results that the edge processing has an influence on the failure strength of the glass.

\section{FRACTURE MECHANICS THEORY}

G lass is an elastic material with a brittle behaviour at failure. Therefore linear elastic fracture mechanics (LEFM) is an ideal theory to model its behaviour. In fact, glass was the material used for the development of the basis of LEFM. In LEFM, mechanical material behaviour is modeled by looking at cracks.

If we think at glass, as a material without flaws and defects, its resistance would be very high. But it doesn't occur in practice because of the presence of the flaws. This phenomenon is explained by LEFM theory.

According to the stress analysis conducted of an elliptical cavity in a uniformly stressed plate, the local stresses about a sharp notch or corner could raise to a level several times higher than the applied stress. It thus became apparent that even submicroscopic flaws might be potential sources of weakness in solids.

Introducing the concept of the stress intensity factor (SIF), expressed to evaluate the failure, glass element fails when this value reaches the critical value $K_{\text {Ic }}$.

The general relationship between the stress intensity factor $K_{\mathrm{I}}$, the nominal tensile stress normal to the crack's plane $\sigma_{n}$, a correction factor $Y$, and some representative geometric parameter $a$, in general the crack depth or half of the crack length, is given by:

$$
K_{I}=Y \sigma_{n} \sqrt{\pi a}
$$

The fracture toughness $K_{I}$, also known as the critical stress intensity factor, is the SIF that leads to instantaneous failure. $K_{I c}$ is a constant value and is also called fracture toughness. Values $K_{I c}$ are available in literature, for soda-lime glass it is 0.75 $\mathrm{MPa} \mathrm{m}^{1 / 2}$. From LEFM is possible obtaining the failure stress form the measure of the depth of the flaw, as shown in [6] and [7].

\section{Stress corrosion}

Glass is noted for its chemical inertness and general resistance to corrosion; therefore, it is used in the chemical industry and in the laboratory when chemical inertness is required. Despite this well-known property, glass is extremely susceptible to stress corrosion cracking caused by water in the environment. This phenomenon is known in the glass literature as static fatigue or delayed failure. The susceptibility of glass to stress corrosion cracking was observed noting a time delay to failure and a loading rate dependence of strength. This effect is an activated process caused by water in the environment. Static fatigue of glass results from the growth of small cracks in the surface of glass under the combined influence of water vapor and applied load.

Actually, glass is time dependent if it is in presence of humidity (only in vacuum it is time-independent). Stress corrosion causes flaws to grow slowly when they are exposed to a positive crack opening stress. A glass element stressed below its momentary strength (e.g. the static load) will still fail after the time necessary for the most critical flaw to grow to its critical size at a particular stress level. 
A kinematic relationship between crack velocity $v$ and stress intensity factor $K_{I}$ exists and it is commonly used for glass lifetime prediction. For values of $K_{I}$ close to the critical value of $K_{I c}$ (that represents the glass toughness), $v$ is independent of the environment and the crack propagates very rapidly (for soda lime silica glass is about $1500 \mathrm{~m} / \mathrm{s}$ ).

In the $v-K_{I}$ logarithmic-curve, $v_{0}$ represents the position and $\mathrm{n}$ is its slope. Below certain threshold stress intensity $K_{t b}$ no crack growth occurs. The value of $v_{0}$ and $n$ parameters are discussed by Haldimann [1], for laboratory condition, $v_{0}$ can be assumed equal to $0.01 \mathrm{~mm} / \mathrm{s}$, instead it is $6 \mathrm{~mm} / \mathrm{s}$ in environmental condition. The parameter $n$ is assumed 16 .

According to the theory of fracture mechanics, glass failure stress was defined using stress intensity factor $K_{I}$. This equation is only valid in testing conditions where stress corrosion could be eliminated. If the subcritical crack growth is considered, the crack propagates as a function of loading time. This approach is presented by Haldimann [1], in which the crack velocity parameter $v_{0}$ has the dimension of a velocity, instead $n$ is dimensionless.

$$
a(t)=\left(a_{i}{ }^{\frac{2-n}{n}}+\frac{2-n}{n} v_{0} K_{I c}^{n}(Y \sqrt{\pi})^{n} \int_{0}^{t} \sigma(\tau) d \tau\right)^{\frac{2-n}{n}}
$$

The same relation can be expressed in terms of the value $\sigma$ with a static loading time. It is possible to obtain the failure stress $\sigma_{f}$, knowing the $t_{f}(\mathrm{~s})$, i.e. the failure loading time and assuming $a_{c i}(\mathrm{~m})$ corresponding to the initial crack flaw depth.

$$
\sigma_{f}\left(t_{f}\right)=\left(\frac{2}{t_{f}(n-2) \nu_{0}\left(Y \sqrt{\pi} / K_{I c}\right)^{n} a_{c i}^{\frac{n-2}{2}}}\right)^{\frac{1}{n}}
$$

Until a certain loading time, the inert strength is considered to determine the failure. But with the increase of the loading time, in presence of the stress corrosion, the relation (3) is used to determine the failure strength. The theoretical transition time loading between inert condition and time-depending condition, $t_{r e f}$, that could be considered a reference value is obtained by Eq. (1) and (3).

$$
t_{r e f}=\frac{2 a}{(n-2) v_{0}}
$$

It $t>t_{\text {ref }}$ the strength decreases following (3), instead if $k<t_{\text {ref }}$ the failure is assumed to follow the inert strength level.

\section{Fracture surface analysis}

Fractography can bring quantitative information about loading condition at failure. The fracture surface is a source of information to determine the failure condition. Fractography of brittle materials is used to determine the origin of failure during strength testing, as in [8] and [9]. In general, this origin can be traced to material inhomogeneities, such as pores and micro-cracks, which occur due to machining (surface defects). Fracture features, such as mirror, mist and hackle zones, and crack branching, are formed upon failure.

The fracture surface is a mirror zone that forms around the critical flaw, at the cross-section of the failed specimen. Under a failure stress, once the critical flaw starts to propagate, mirror boundary hackle lines are created after radiating crack reaches terminal velocity.

The failure stress $\sigma_{f}$, i.e. the maximum principal tensile stress at the fracture origin, was approximately proportional to the reciprocal of the square root of the mirror radius (radius of the mirror/ mist boundary) $r_{m}$ :

$$
\sigma_{f} r_{m}^{1 / 2}=B
$$

Where $B$ is a constant value $\left(\mathrm{MPa}^{1 / 2}\right)$, that depends on the material properties. However, limited informations are available about the time-dependency of glass strength in relation to the mirror radius. The relation (5) related to brittle materials, is valid for inert strength values. The time-dependency in glass strength is not taken in consideration in the measurement of the mirror radius.

The analysis and interpretation of fracture mirror sizes in brittle materials are given in [5]. Fracture mirrors are revealing fractographic markings that surround a fracture origin in brittle materials. The fracture mirror size may be used with known fracture mirror constants to estimate the stress in a fractured component. Alternatively, the fracture mirror size may be used in conjunction with known stresses in test specimens to calculate fracture mirror constants. 
The relationship (6), called the crack branching equation, is generally accepted but its application is not always easy because reading the fracture pattern becomes quite complex for high stresses values that produce the failure.

The crack branching equation is useful to evaluate the failure stress from the measure both of the mirror radius $r_{\mathrm{m}}$, both of the hackle radius $m_{\mathrm{h}}$, both of the half branching length $n_{\mathrm{b}}$ (The subscripts $m, h, b$, represent respectively the mirror, the hackle and the branch):

$$
\sigma_{f}-\sigma_{a r}=\alpha r_{m}^{-1 / 2}
$$

where $\sigma_{a r}$ is interpreted as being an apparent residual compressive surface stress and $\alpha$ is a constant value. Finally, all three branching constants $\alpha_{m}, \alpha_{b}$ and $\alpha_{b}$ as well as the corresponding apparent residual stresses $\sigma_{a r}$ were determined in recent studies, [10], and presented in [2] and summarized in Tab. 1.

\begin{tabular}{ccc}
\hline & $\alpha\left[\mathrm{MPa} \mathrm{m}^{1 / 2}\right]$ & $\sigma_{\mathrm{ar}}[\mathrm{MPa}]$ \\
Mirror & 1.98 & 9.6 \\
Hackle & 2.11 & 9.1 \\
Branch & 2.18 & 10.7 \\
\hline
\end{tabular}

Table 1: Parameters of the crack branching equation for annealed glass.

\section{Size effect}

The size of the loading area has an influence on the failure stress [11]. This effect can be explained with the Weibull theory referring to the fact that a larger panel is more likely to have a large flaw in a high stress region, than small panel [12]. The relation that explains the size effect is:

$$
\frac{\sigma_{1}}{\sigma_{2}}=\left(\frac{V_{e f f .2}}{V_{e f f .1}}\right)^{\frac{1}{\beta}}
$$

where $\sigma_{1}$ and $\sigma_{2}$ are tensile stress value for two elements of different sizes, of effective volumes $V_{\text {eff.1 }}$ and $V_{\text {eff.2. }}$. The $\beta$ parameter can be calculated according to Weibull fit in EN 12603 [13].

In a recent study [14], it was tested the influence of the size effect testing a large number of samples. It is notice that larger elements tend to have a greater probability of larger flaws. The results demonstrate some differences between experimental and theoretical rates of the characteristic strength values, so, it means that the size effect has to be investigated more thoroughly.

\section{NUMERICAL RESULTS}

$\mathrm{F}$ ive sets of elements were tested in four points bending test. In Tab. 2 the geometrical dimensions, the edge finishing and the number of the samples are shown. Sets A and B present the same geometry, but different edge finishing. Sets $C$ and $D$ have another size, in which the length is bigger than that of the former series. Finally, the size of the samples of set $\mathrm{E}$ is the biggest. Sets $\mathrm{A}, \mathrm{C}$ and $\mathrm{E}$ present ground edges; instead sets B and D consist of glass beam with only cut edge. The ratio between height, $h$, and length $l$, of the elements of the various series is almost constant. The ratio between the load span, $s$, and the support span, $s_{s}$, are almost constant too.

\begin{tabular}{lccccccccc}
\hline & $\begin{array}{c}\mathrm{b} \\
{[\mathrm{mm}]}\end{array}$ & $\begin{array}{c}\mathrm{h} \\
{[\mathrm{mm}]}\end{array}$ & $\begin{array}{c}\mathrm{l} \\
{[\mathrm{mm}]}\end{array}$ & $\begin{array}{c}\text { Edge } \\
\text { finishing }\end{array}$ & $\begin{array}{c}\mathrm{N}^{\circ} \text { of } \\
\text { samples }\end{array}$ & $\mathrm{s}_{\mathrm{s}}[\mathrm{mm}]$ & $\begin{array}{c}\mathrm{l}_{\mathrm{s}} \\
{[\mathrm{mm}]}\end{array}$ & $\mathrm{h} / 1$ & $\mathrm{l}_{\mathrm{s}} / \mathrm{s}_{\mathrm{s}}$ \\
SET A & 8 & 50 & 400 & Ground & 25 & 360 & 120 & 49.56 & 0.33 \\
SET B & 8 & 50 & 400 & Cut & 25 & 360 & 120 & 35.01 & 0.33 \\
SET C & 8 & 50 & 550 & Ground & 19 & 500 & 160 & 47.41 & 0.32 \\
SET D & 8 & 50 & 550 & Cut & 18 & 500 & 160 & 109.7 & 0.32 \\
SET E & 8 & 100 & 1100 & Ground & 20 & 1000 & 300 & 56.94 & 0.30 \\
\hline
\end{tabular}

Table 2: Geometrical dimensions, edge finishing and number of the samples for the various sets of glass elements. 
The specimens were subjected to in-plane four-point bending tests in a universal UTS testing machine (Fig. 1-a). The specimens were loaded at a stress rate of $0.75 \mathrm{MPa} / \mathrm{s} \pm 0.15 \mathrm{MPa} / \mathrm{s}$. For each sample the failure load $P_{f}$, the time at failure $t_{f}$ and the maximum displacement in the midspan $w_{f}[\mathrm{~mm}]$ was collected. The test ends when the beams collapse. The failure stress values or tensile strength value $f$, were calculated with the following equation:

$$
f=\frac{\left(\frac{P_{f}}{2}\right) d}{b \frac{b^{2}}{6}}=\frac{3 P_{f} d}{b b^{2}}
$$

where $d[\mathrm{~mm}]$ is the distance between the load and the support; $b[\mathrm{~mm}]$ is the width of the specimen and $b[\mathrm{~mm}]$ is the height of the specimen. The failure initiated at the loaded area linked to the tensile stresses at the edge, creating a crack opening. The test set-up used is illustrated in Fig. 1-b).

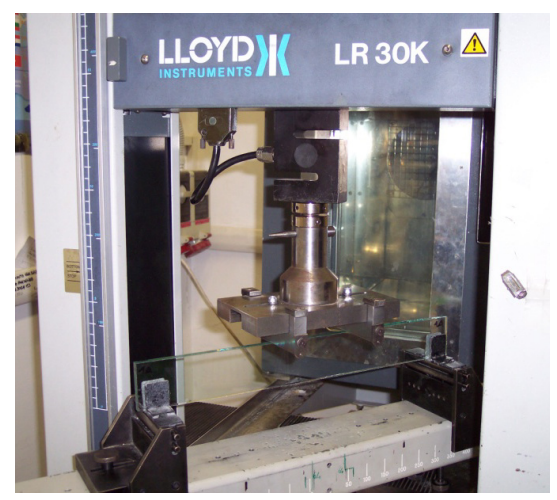

a)

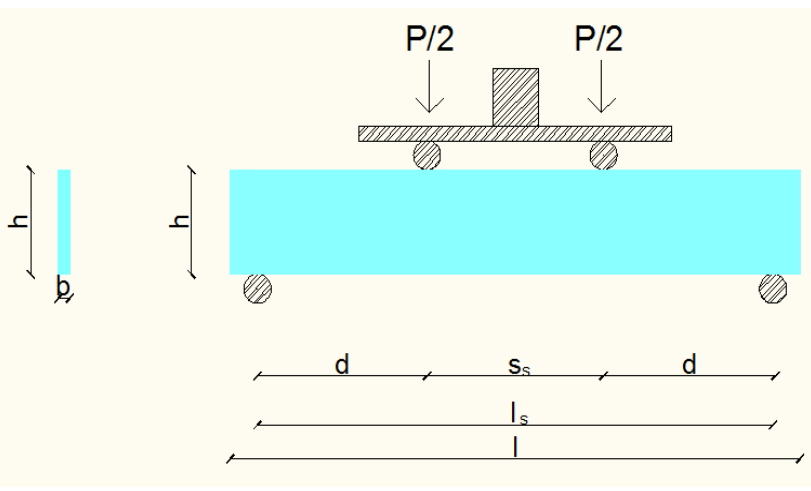

b)

Figure 1: Test set-up used for in-plane four point bending tests (for each sample).

The mean results for each set are shown in Tab. 3. As first result of the bending tests, it is possible to observe that the mean failure load for series A, having ground edges is higher than the one of series B. Instead comparing series C and D, the mean failure load for the set of beams with cut edge is slightly higher than the one with ground edge. The failure happened always in the zone inside the load span: cracks propagate from the tensile zone, at the bottom edge, to the compressive zone, in which the cracks branch out into several branches. The moment at failure was determined by the failure load.

\begin{tabular}{lccccc}
\hline & $P_{f}[\mathrm{~N}]$ & $t_{f}[\mathrm{~s}]$ & $M_{f}[\mathrm{Nmm}]$ & $f[\mathrm{Mpa}]$ & $w_{f}[\mathrm{~mm}]$ \\
SET A & 2290.14 & 75.54 & 148859.10 & 44.24 & 2.52 \\
SET B & 1864.60 & 66.56 & 121199.26 & 36.43 & 2.22 \\
SET C & 1624.27 & 50.10 & 138063.26 & 40.81 & 2.09 \\
SET D & 1925.89 & 52.77 & 163700.74 & 45.65 & 2.76 \\
SET E & 3446.28 & 59.88 & 603098.64 & 40.82 & 2.79 \\
\hline
\end{tabular}

Table 3: Mean values at failure for each series.

Observing the various failures, it was possible to identify some particular crack patterns that are frequently presented (Fig. 2). The crack pattern depends on the strength of the beams and directly it depends on the flaw measure. Beams having bigger strength (the flaws are small) presents more glass fragments, instead beams that collapse in a few number of pieces presents big flaws.

The failure happened always in the zone inside the load span: cracks propagate from the tensile zone, at the bottom edge, to the compressive zone, in which the cracks branch out into several branches. 
a)

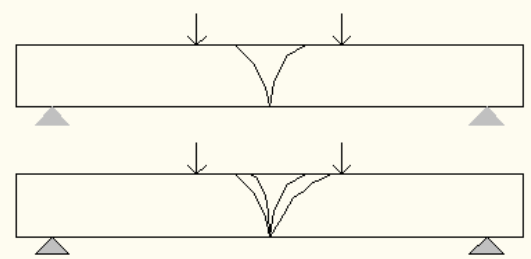

c)

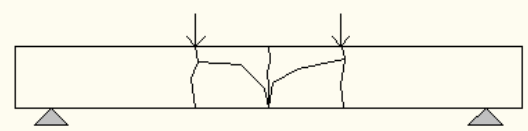

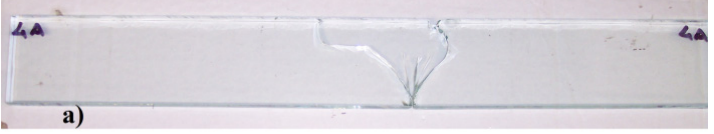
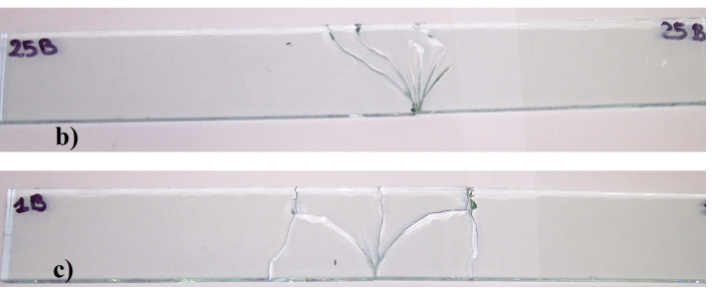

Figure 2: Crack patterns of glass beams.

As regard the test performed, the experimental results were analyzed with the LEFM theory and the glass strength was analyzed with a statistical study using two-parameter Weibull distribution fitting quite well the failure stress data.

\section{LEFM analysis}

Glass specimens were examined using an optical microscope with polarized light after the failure. Important information on the flaw sizes, the fracture origin and the fracture mirror sizes were collected. In the following Fig. 3-b some examples of fracture surface are presented. It is easy to identify the flaw and the mirror zone (shown in Fig. 3-a).
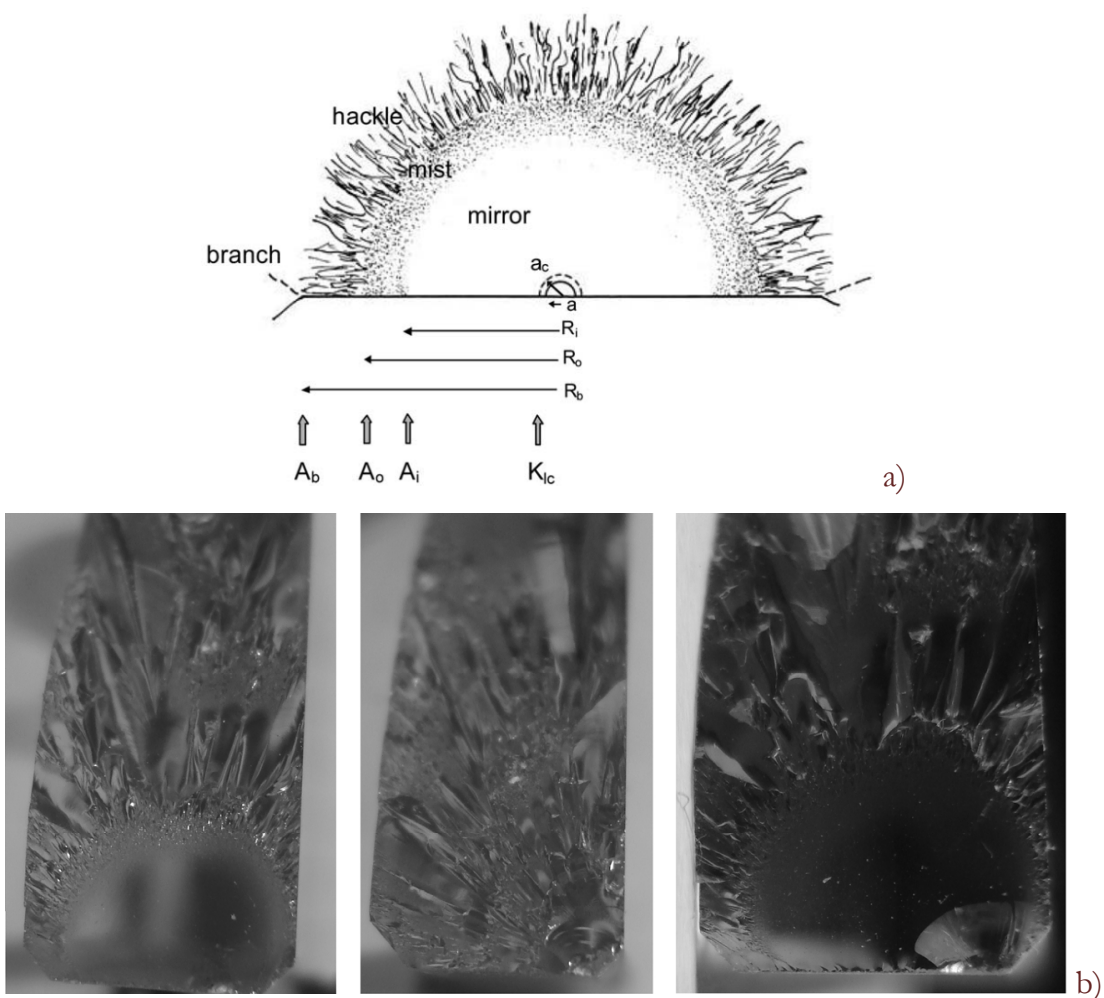

Figure 3: Illustration of the depth flaw and of the mirror radius.

The results of the post-fracture analysis are summarized in Tab. 4, where the mean values of the mirror radius and of the flaw depth are presented for each series. It is possible to observe that the ratio between the mirror radius, $r_{m}$, and the flaw depth, $a$, is almost constant and it is about $9 \div 10$.

The strength $\sigma_{f}\left(t_{f}\right)$ is obtained by Eq. (3) knowing the measure of the flaw depth, $a$, the time at failure, $t_{f}$ and the critical value of $K_{I c}$. The value of $v_{0}$ and $n$ parameters are discussed in [1]; for laboratory condition, $v_{0}$ can be assumed equal to 0.01 $\mathrm{mm} / \mathrm{s}$; the parameter $n$ is assumed 16. The geometry factor, $Y$, is defined as a constant value for various edge crack 
configurations; it is chosen by literature, [1], observing each crack pattern. In Tab. 4 the mean values of the strength, $\sigma_{f}\left(t_{f}\right)$, the time reference, $t_{r e f}$, and the inert strength, $\sigma_{f}\left(t_{r f f}\right)$, are shown, too.

\begin{tabular}{lcccccc}
\hline & $r_{m}[\mathrm{~mm}]$ & $a[\mu \mathrm{m}]$ & $r_{m} / a$ & $\sigma_{f}\left(t_{f}\right)[\mathrm{MPa}]$ & $t_{r f}[\mathrm{~s}]$ & $\sigma_{f}\left(t_{r f}\right)[\mathrm{MPa}]$ \\
SET A & 2.50 & 292.4 & 9.0 & 52.91 & 4.18 & 54.03 \\
SET B & 3.89 & 456.1 & 8.4 & 45.43 & 6.52 & 46.50 \\
SET C & 2.28 & 352.5 & 10.1 & 50.74 & 5.04 & 50.53 \\
SET D & 2.31 & 247.1 & 9.4 & 50.14 & 3.53 & 50.21 \\
SET E & 2.56 & 271.5 & 10.0 & 55.01 & 3.88 & 54.91 \\
\hline
\end{tabular}

Table 4: Mean values of the failure parameters, failure strength, time reference and inert strength for each series.

Glass strength was analyzed with a statistical study using two-parameter Weibull distribution fitting the failure stress data as presented in [15]. The two parameter Weibull function is expressed as:

$$
G(x)=1-\exp \left[-\left(\frac{x}{\theta}\right)^{\beta}\right]
$$

where:

$\mathrm{G}(\mathrm{x})$ means a distribution function of $\mathrm{x}$ percentage of failure;

$\theta$ is a scale parameter in Weibull two-parameter distribution;

$\beta$ is respectively a shape parameter.

Weibull two-parameter probability distribution permits a correct analysis of glass strength. In Tab. 5 the two parameter of the Weibull distribution are presented.

\begin{tabular}{lcc}
\hline & $\theta$ & $\beta$ \\
SET A & 4.161 & 59.555 \\
SET B & 9.241 & 48.014 \\
SET C & 4.694 & 55.128 \\
SET D & 6.639 & 54.182 \\
SET E & 3.166 & 63.726 \\
\hline
\end{tabular}

Table 5: Parameter $\theta$ and $\beta$ of the Weibull two-parameter distribution.

The diagram in Fig. 4 shows the fitting of the Weibull distribution for the series A, under the hypothesis that the specimens contain a random flaw population. The same diagrams were obtained for the other set of beams. The stress values vary largely in the range of $16.24 \mathrm{MPa}$ to $97.35 \mathrm{MPa}$. The mean stress values vary in a range of $45.43 \mathrm{MPa}$ to 55.01 $\mathrm{MPa}$. The variation was noticed to exist between edge finishing; values of standard deviation vary from 5.5 to 16.4 for the five series of specimens.

In order to compare the LEFM theory with the failure surface analysis, the parameters for the crack branching equation, $\alpha$ and $\sigma_{a r}$, were determined by a linear regression in the diagram of the failure stresses and the mirror length. The mirror length was measured together with the flaw depth, in the post failure microscopic analysis.

The measured length of the mirror was used to evaluate the crack branching Eq. and to establish a value for the branching constant. The objective is to compare the constants obtained from this analysis, using a trend line, with the ones proposed by the previous studies (Fig. 5). 

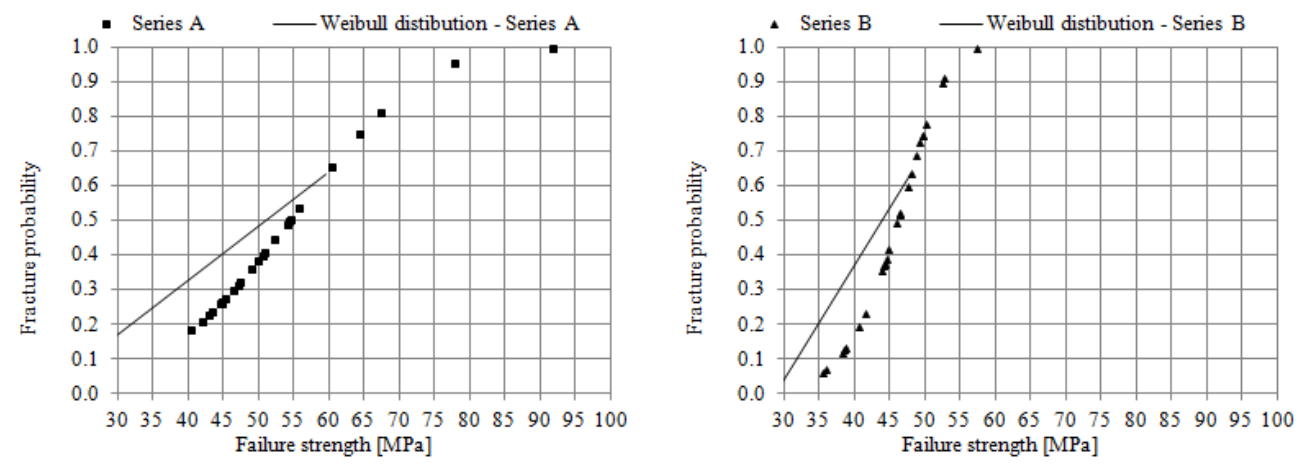

Figure 4: Weibull two-parameter probability distribution for sets A and B.
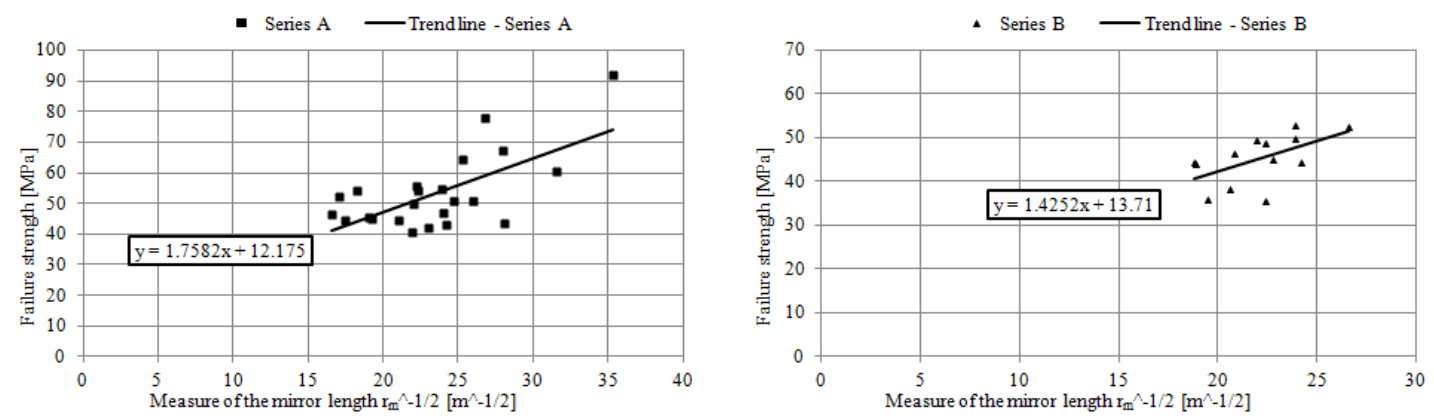

Figure 5: Diagram of the measure of the mirror length $r_{m}\left(\mathrm{~m}^{-1 / 2}\right)$ vs. the failure strength $\sigma_{f}\left(t_{f}\right)$ for sets A and B.

The mean values of the parameters $\alpha$ and $\sigma_{a r}$, calculated using the crack branching Eq., are 2.00 and 11.06. These are slightly higher than the ones proposed in Tab. 1 for the evaluation of the failure stress from the measure of the mirror radius $r_{\mathrm{m}}$, but they are in accordance with the ones proposed by literature.

However, in general the inert strength is higher than the strength at failure time, when stress corrosion is considered. Values of the strength at failure time, $\sigma_{f}\left(t_{f}\right)$, and values of the inert strength, $\sigma_{f}\left(t_{\text {ref }}\right)$, are obtained and compared in the previous Tab. 4.

As explained by the theory, inert strength is higher than the strength measured at failure, $\sigma_{f}\left(t_{f}\right)$ (Tab. 4). Stress corrosion law was obtained by the mean values for each series of beams and it was plotted together with the mean strength for each lot of samples in the following Fig. 6.

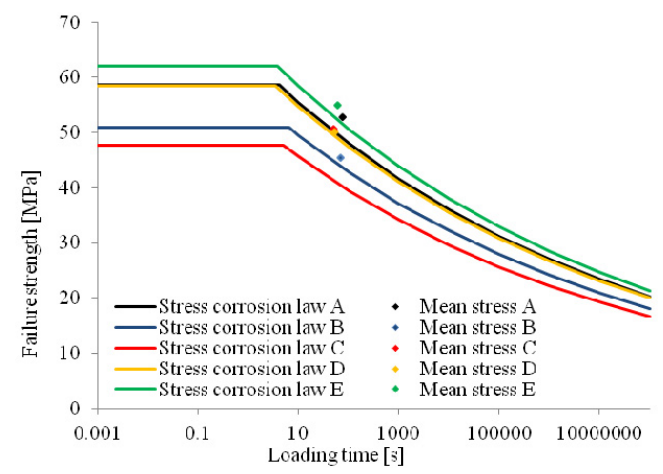

Figure 6: Stress corrosion law for each series of samples.

Size effect was studied considering sets A and C, having ground edges. Larger bodies generate lower mechanical strength values taking into account the higher probability of finding natural heterogeneities (flaws or cracks). In Weibull weakest link theory, the ratio between the mean mechanical strength values and the ratio of the effective volumes of the specimens leads to a strength dependency on body size as explained in the relation (7). For the analysis on the size effect for the 
ground edge samples, the results in terms of failure strength show that set E present the greater values, that is higher than the failure strength of sets $A$ and $C$; for this reason set $E$ was excluded from the analysis. Instead the value of $\sigma_{\mathrm{f}}\left(\mathrm{t}_{\mathrm{f}}\right) \mathrm{f}_{\mathrm{f}} \mathrm{fr}_{\mathrm{f}}$ set $A$ is higher than the one of the set $C$. In the latter case shorter samples present higher stresses that are what we expect by the theory: only sets A and B were compared.

The analysis permits to obtain the same value 1.05 form the ratio of the strength $\sigma_{\mathrm{A}} / \sigma_{\mathrm{C}}$ that is equal to the corresponding $\left(V_{\text {eff,C }} / V_{\text {eff, }, A}\right)^{1 / \beta}$.

\section{CONCLUSIONS}

$\mathrm{F}$ law characterization on glass beams was studied. The experiments performed, confirm the applicability of the failure prediction theories commonly applied to explain the failure strength of glass.

Each specimen was assumed to fail in mode I (in LEFM theory, mode I is a normal-opening, while modes II and III are shear sliding modes); the failures initiated inside the loaded area. The analysis and the measurements executed confirm the relation existing between flaw size and strength: the larger the critical flaw initiating the failure, the lower the strength. An equivalent relation is valid for the mirror radius: the larger the mirror radius, the lower the strength.

The edge finishing produces advantage in terms of strength. The strength of ground edge glass is higher than the one of simply cut edge glass. The edge processing produces a reduction of the maximum depth of the flaw and an increase of the strength.

Furthermore it was observed that the failure strength had no linear relation to flaw depth. In analogy, the fracture surface analysis shows that the failure strength had no linear relation to the mirror radius.

In the LEFM the values of the geometric parameter $Y$, were estimated by observing the fracture surface, in order to obtain the failure strength for each sample. In the fracture surface analysis, constant values $\alpha$ and $\sigma_{a r}$, were confirmed using a linear regression law, fitting the measured data.

The observations on the size effect show that the bigger is the length of the beam, the bigger is the probability to find flaws. In general, beams with edge processing, as grinding or polishing is recommended.

\section{REFERENCES}

[1] Haldimann, M., Fracture strength of structural glass elements - analytical and numerical modeling, testing and design, PhD These n. 3671, EPFL, Lausanne, Switzerland (2006).

[2] Haldimann, M., Luibe, A., Overend, M., Structural use of glass, Structural Engineering Documents, IABSE - AIPC IVBH 10 (2010).

[3] Lindqvist, M., Vandebroek, M., Louter, C., Belis, J., Influence of edge flaws on failure strength of glass, In: Proceedings of GPD 2011, Tampere, Finland, (2011) 126-129.

[4] Vandebroek, M., Belis, J., Louter, C., Van Tendeloo, G., Experimental validation of edge strength model for glass with polished and cut edge finishing, Engineering Fracture Mechanics, 96 (2012) 480-489.

[5] ASTM C1678-10, Standard practice for fractographic analysis of fracture mirror sizes in ceramics and glasses, America Society for Testing materials (2010).

[6] Carpinteri, A., Meccanica dei materiali e della frattura, Pitagora Editrice, Bologna, (1992).

[7] Lawn, B.R., Fracture of brittle solids. 2nd ed. Cambridge: Cambridge University Press, (1993).

[8] Dielhof, M. H., Dortmans, L. J. M. G., de With, G., Fractography of Borosilicate Tested in Three- and Four-Point Bending Glass, Journal of the European Ceramic Society, 12 (1993): 215220

[9] Conoway, J. C., Mecholsky, J. J., Use of crack branching data for measuring near-surface residual stresses in tempered glass, Journal of the American Ceramic Society, 72 (9) (1989) 1584-1587.

[10] Zaccaria, M., Overend, M., Validation of a simple relationship between the fracture pattern and the fracture stress of glass, In: Engineered Transparency. International Conference at Glasstec, Düsseldorf, Germany, (2012).

[11] Fischer, H., Rentzsch, W., Marx, R., A modified size effect model for brittle non-metallic materials. Engineering Fracture Mechanics, 69 (2002) 781-791.

[12] Quinn, G. D., Weibull Effective Volumes and Surfaces for Cylindrical Rods Loaded in Flexure, Journal of the American Ceramic Society, 86 (3) (2003) 475-479.

[13] EN 12603:2002, Glass in building - Procedures for goodness of fit and confidence intervals for Weibull distributed glass stength data, CEN (2002). 
[14] Vandebroek, M., Lindqvist, M., Louter, C., Belis, J., Edge strength of cut and polished glass beams, In: Proceedings of GPD 2011, Tampere, Finland, (2011) 476-479.

[15] Weibull, W., A statistical theory of the strength of materials, Royal Swedish Institute for Engineering Research, 151 (1939). 